\title{
PLC based Segregation of Scrap Material
}

\author{
Mangesh B. Nagapure*, Dr. R. M. Deshmukh** \\ *(Student, Dept. of Electronics \& Telecommunication Engineering, SGBAU University, Amravati, India \\ ** (HOD, Dept. of Electronics \& Telecommunication Engineering, SGBAU University, Amravati, India
}

\begin{abstract}
This paper describe segregation of scrap materials using automation system. With the growing population rate, the amount of waste being produced is also increasing at a very faster rate. It is also posing a very serious problem at the industrial and domestic level to manage the wastes being dumped everywhere as landfill waste. So, it is very crucial to have some system to manage waste automatically which is currently not there. Prime Minister Modi's mission of Swaccha Bharat Abhiyan can also be successfully implemented by the proposed system. The paper proposes a novel method where the provision is given to separate out metal and nonmetal waste into respective bins by the sensing of different sensors incorporated along the conveyor belt. Pieces of glass, paper, wood and metallic materials are separated out from proposed work. Using the segregation, most of the metal and nonmetal components like paper, glass, plastic increases the economic value of the waste to its best. For every scrap separation system, a higher level of automation demands more and more accurate programming device. So, we are using programmable logic controller (PLC) as main component.
\end{abstract}

Keywords: Programmable Logic Controller (PLC), Sensors, Robotic arm, Conveyor Belt, Relays.

\section{INTRODUCTION}

The purpose of this project is to segregate the metal and nonmetal waste for the industrial and domestic use. Due to the environmental aspect as well as increasing prices for raw materials, scrap separation is a global topic and also the business model of the future. The advantages of scrap separation system are to improve the results in energy savings, better environmental performance, minimize raw materials wastage and reduce manufacturing costs. These benefits also categorized as to improved scrap management systems. The advantage of PLC is the automation with a relatively small amount of cabling and a low error rate. Productivity, flexibility and efficiency with using only a few contactors specify the controller. The whole system is completed by modifications and extensions of functions as well as by communication with other devices via analog, digital and serial interfaces.

Automation or automatic control is the use of various control systems for operating equipment such as machinery, processes in factories, boilers and heat treating ovens, switching on telephone networks, steering and stabilization of ships, aircraft and other applications with minimal or reduced human intervention. Some processes have been completely automated. The biggest benefit of automation is that it saves labor; however, it is also used to save energy and materials and to improve quality, accuracy and precision.

The main advantages of automation are:-

- Increased throughput or productivity.

- Improved quality or increased predictability of quality.

- Improved robustness (consistency), of processes or product.

- Increased consistency of output.

- Reduced direct human labor costs and expenses.

\section{PLC SYSTEM}

A PLC is a digitally operating electronic device which uses a programmable memory for internal storage of instructions for implementing specific functions, such as logic sequencing, timing, counting and control through digital or analog input/output modules. A programmable logic controller, also called a PLC or programmable controller, is a computer- type device that is used to control equipment in an industrial facility. PLC's are real-time controllers with cyclic behavior. Each cycle consists of three steps. The first step scans the inputs to the controller and maps a picture of the input status into the controller memory. After that a program stored in the controller memory is processed, taking into account the memory image of the inputs. As a result, an image of the outputs is produced. In the third step the image of the output variables is mapped to the actual outputs. 


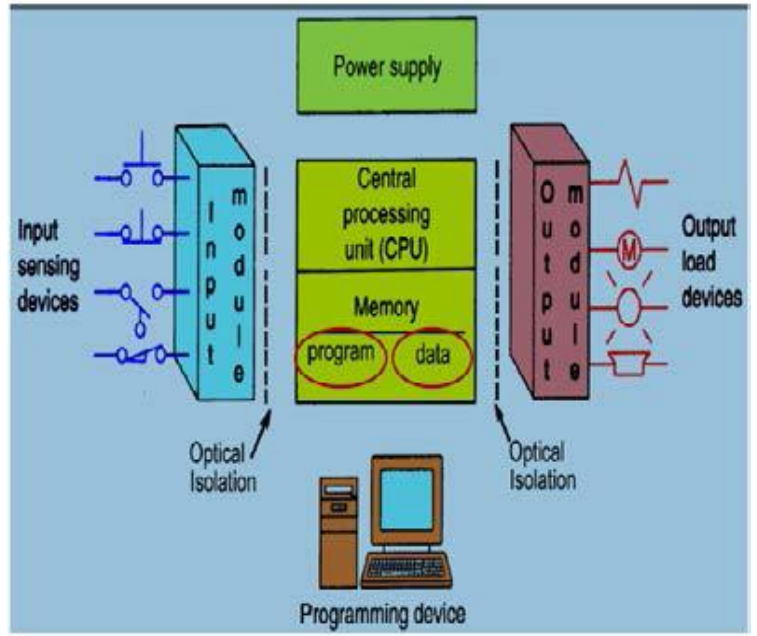

Fig. 2.1 Block diagram of PLC system

There are three basic components in a PLC system: 2.1.1 The PLC processor - It stores the control program and data in its memory. Reads the status of connected input devices \& executes the control program. Commands connected outputs to change state based on program execution For example: Turn a light on, start a fan, adjust a speed, or temperature and Comes in various physical forms.

2.1.2 I/O Modules - They physically connect to field devices. Input modules convert electrical signals coming in from input field devices such as pushbuttons, to electrical signals that the PLC can understand. Output modules take information coming from the PLC and convert it to electrical signals the output field devices can understand, such as a motor starter, or a hydraulic solenoid valve. I/O comes in various forms.

2.1.3 Power Supply - A power supply is needed to provide power to the PLC and any other modules. Power supplies come in various forms:

- Power supply modules that fit into one of the slots in a chassis.

- External power supplies that mount to the outside of a chassis.

- Stand alone power supplies that connect to the PLC or I/O through a power cable.

- Embedded power supplies that come as part of the PLC block.

\section{HARDWARE CONFIGURATION}

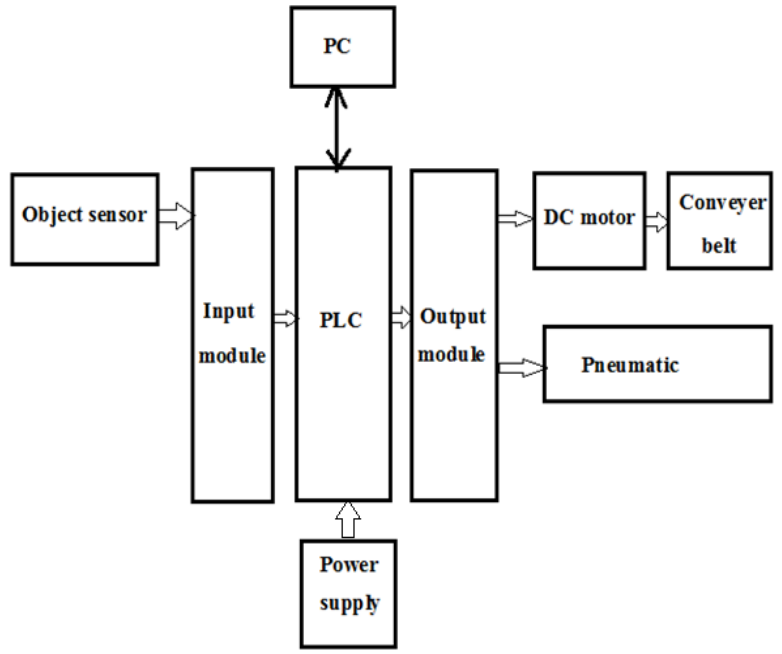

Fig. 3.1 Block diagram of Segregation of Scrap materials with PLC

Fig. 2 shows the block diagram which consists of three units- sensing units, controlling units, segregation units.

\subsubsection{Sensors}

A sensor is a device that measures a particular characteristic of an object or system. Some sensors are purely mechanical, but most sensors are electronic, returning a voltage signal that can be 
converted into a useful engineering unit. Sensors are used in everyday objects such as touch-sensitive elevator buttons (tactile sensor) and lamps, which dim or brighten by touching the base. There are also innumerable applications for sensors, which include cars, machines, aerospace, medicine, manufacturing and robotics.

3.1.1.1 Photoelectric Sensor - A photoelectric sensor, or photo eye, is a device used to detect absence, or presence of an object by using a light transmitter, often infrared, and a photoelectric receiver. They are used extensively in industrial manufacturing. There are three different functional types: opposed (through beam), retro-reflective, and proximity sensing (diffused), figure 3 shows one of Photo types.

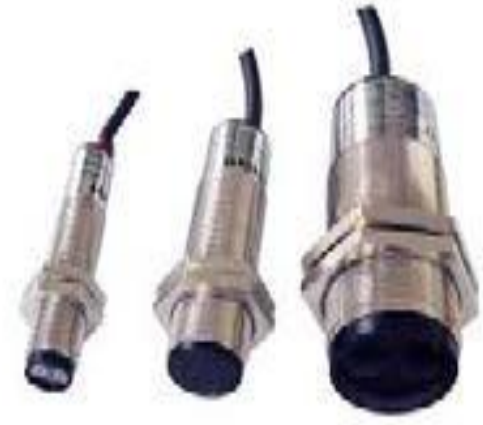

Fig.3.1.1.1 Photoelectric Sensor Sample.

3.1.1.2 Inductive Proximity Sensors - Inductive sensors use currents induced by magnetic fields to detect nearby metal objects. All of inductive sensors consist of four basic elements; the oscillator, which produces the electromagnetic field, the coil, which generates the magnetic field, the detection circuit, which detects changes in the field when an object enters it and the output circuit which produces the output signal as shown in figure

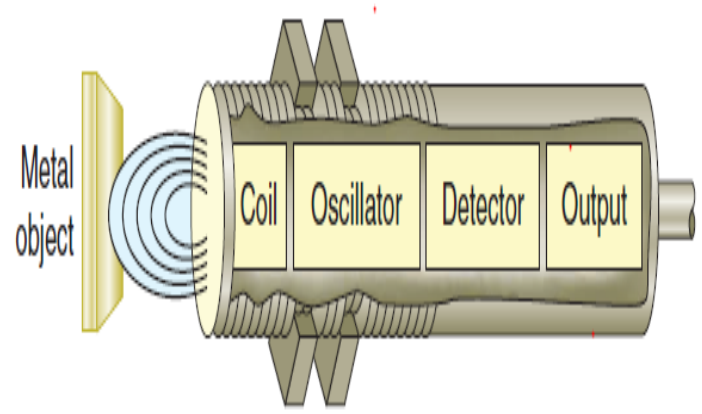

Fig. 3.1.1.2 Inductive Proximity Sensor Structure

\subsubsection{Conveyor Belt}

A conveyor belt is one of the main important types of conveyor systems. The belt is a loop of flexible material used to mechanically link two or more rotating shafts, most often parallel. A belt conveyor system consists of two or more pulleys (sometimes referred to as drums), with an endless loop of carrying medium that rotates about them. One or both of the pulleys are powered, moving the belt and the material on the belt forward. The powered pulley is called the drive pulley while the unpowered pulley is called the idler pulley. There are two main industrial classes of belt conveyors; Those in general material handling such as those moving boxes along inside a factory and bulk material handling such as those used to transport large volumes of resources and agricultural materials, such as grain, salt, coal, ore, sand, overburden and more.

\subsubsection{Motor}

DC motors have been used in industrial applications for years. Coupled with a DC drive, DC motors provide very precise control. DC motors can be used with conveyors, elevators, extruders, marine applications, material handling, paper, plastics, rubber, steel, and textile applications 


\subsubsection{Robotic Arm}

A Robotic Arm attached to the system delivers fast, accurate and repeatable movement. When metal is detected by the metal detector, the conveyor belt stops and control signal given to the Robotic arm by PLC is drop/push the metal particles into its respective bin.

\section{PROPOSED WORK \& OBJECTIVES}

We are developing a prototype for separating out metal and nonmetal particles using Programmable Logic Controller (PLC) for the domestic and industrial use. In this system the scrap materials (i.e. metal and nonmetal waste) will be fed onto the conveyor belt, object sensors will detect the particles on the conveyor belt and start the rotation of the conveyor belt. Then, metal sensors which are clamped to the conveyor belt will sense the metal waste and stop the conveyor belt. A segregator attached to the system will push the metal waste into its respective bin, which will be carried for further operations and the nonmetal waste are automatically fed into the waste dust bin.

The objectives are:-

* Designing of the Industrial/Home automation systems.

* PLC works as the core of the system which controls the whole setup.

* Controlling robotic arm by using Ladder diagram.

* Sensor is used to detect the presence of the object on the conveyor belt.

* To take action on input and output as per program, the logic feed to PLC.

* Inputs suitable for switches and proximity switches.

* Outputs capable of driving solenoid valves or indicator lights.

* By producing such system, the scope is in the field of Manufacturing Industries.

* Interlocks for Safety purpose and for high production rate.

\section{ADVANTAGES}

$\neg$ Increases in production capacity and quality.

$\neg$ Decreases in total manufacturing cost.

$\neg$ Less manual work.

$\neg$ Easy analysis.

$\neg$ Improves productivity.

$\neg$ Time saving and efficient

\section{DISADVANTAGES}

$\neg$ Costly for small scale industries.

$\neg$ Segregation mechanism is time based hence

Frequent monitoring is required.

$\neg$ PLC devices are proprietary.

\section{CONCLUSION}

The soft wiring advantage provided by programmable controllers is Tremendous. In fact, it is one of the most important features of PLCs. Soft wiring makes changes in the control system easy and cheap. If it want a device in a PLC system to behave differently or to control a different process element, all have to do is change the control Program. In a traditional system, making this type of change would involve physically changing the wiring between the devices, a costly and time-consuming endeavor.

\section{REFERENCES}

[1] M Nidhi Mishra1, Rakhi T. Waghmare2, Rani B. Phulpagar3, Pooja A. Londhe4, "Plc Based Scrap Management System",Rani B. Phulpagar et al Int. Journal of Engineering Research and Applications ISSN : 2248- 9622, Vol. 4, Issue 3( Version 1), March 2014.

[2] S.M .Dudhal1, B. S. Jonwal2, Prof. H. P. Chaudhari3, "Waste Segregation Using Programmable Logic Controller", International Journal For Technological Research In Engineering Volume 1, Issue 8, April-2014 ISSN.

[3] Joanna Marie M. Baroro, Melchizedek I. Alipio, Michael Lawrence T. Huang,Teodoro M. Ricamara, Angelo A. Beltran Jr..," Automation of Packaging and Material HandlingUsing Programmable Logic Controller",(ISSN: 2277 1581), Volume No. 3, Issue No. 6, pp: 767 770. 1 June 2014.

[4] Joice Johny1, Abin Joy2, Della Sunny3, Basil M Joseph4 \& Shaji M Jamal5 , "Automatic Plastic Separating Technology For Solid Waste Disposal", International Journal of Civil, Structural, Environmental and Infrastructure Engineering Research and Development (IJCSEIERD)ISSN 22496866Vol. 3, Issue 2, Jun 2013, 99-108 @) TJPRC Pvt. Ltd

[5] John W. Webb, Ronald A. Reis, "Programmable Logic Controllers: Principles and Application", Edition $5^{\text {th }}$, Publisher- Eastern Economy Edition.

[6] Guo, L., Pecen, R., "Design Projects in a Programmable Logic Controller (PLC) Course in Electrical Engineering Technology", ASEE Annual Conference \& Exposition, 2008.

[7] Prof. Mr. P. Balramdu, Prof. Mr. Manoj Kumar, Mr. Chape Laxman Murlidhar, Mr.Wankhade Sachin Sudamrao, Mr.Phalke Ulhas,Mr.Kotkar Narhari Ramkrushna, " Remote Monitoring and Sorting System for Waste Material 
Management Using RFID”,International Journal of Advanced Research in Computer Engineering \& Technology (IJARCET) Volume 3 Issue 10, October 2014.

[8] Subhasini Dwivedi, Michael Fernandes, Rohit D'souza, “A Review on PLC based Automatic Waste Segregator", International Journal of Advanced Research in Computer Engineering \& Technology (IJARCET) Volume 5 Issue 2, February 2016.
Books:

[1]. W. Bolton, Programmable Logic Controllers, (Fifth Edition, Newnes, 2009 ISBN 978-1- 85617-751-1, Chapter 1)

[2]. Johnson, C. D., Process Control Instrumentation Technology, (Prentice Hall, 2006).

[3]. Petruzella, F. D., Programmable Logic Controllers, (McGraw Hill, 2005). 